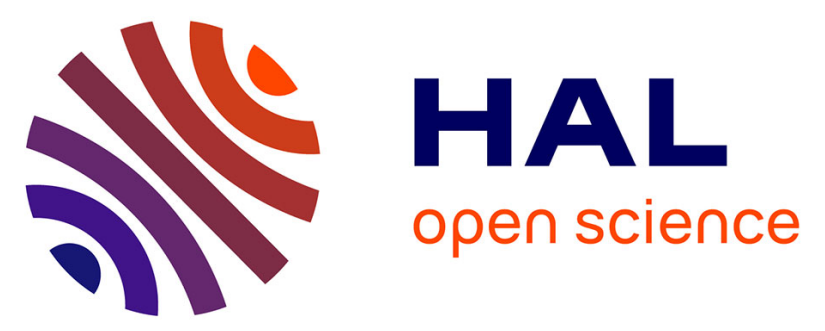

\title{
Versatility of bilayer metal oxide coatings on silver nanowire networks for enhanced stability with minimal transparency loss
}

Sara Aghazadehchors, Viet Huong Nguyen, David Munoz-Rojas, Carmen Jiménez, Laetitia Rapenne, Ngoc Duy Nguyen, Daniel Bellet

\section{To cite this version:}

Sara Aghazadehchors, Viet Huong Nguyen, David Munoz-Rojas, Carmen Jiménez, Laetitia Rapenne, et al.. Versatility of bilayer metal oxide coatings on silver nanowire networks for enhanced stability with minimal transparency loss. Nanoscale, 2019, 11 (42), pp.19969-19979. 10.1039/C9NR05658K . hal-02314439

\section{HAL Id: hal-02314439 \\ https://hal.science/hal-02314439}

Submitted on 7 Jan 2021

HAL is a multi-disciplinary open access archive for the deposit and dissemination of scientific research documents, whether they are published or not. The documents may come from teaching and research institutions in France or abroad, or from public or private research centers.
L'archive ouverte pluridisciplinaire $\mathbf{H A L}$, est destinée au dépôt et à la diffusion de documents scientifiques de niveau recherche, publiés ou non, émanant des établissements d'enseignement et de recherche français ou étrangers, des laboratoires publics ou privés. 


\section{Versatility of bilayer metal oxide coatings on silver nanowire networks for enhanced stability with minimal transparency loss}

Received 00th January 20xx, Accepted 00th January 20xx DOI: $10.1039 / x 0 \times x 00000 x$

\begin{abstract}
Sara Aghazadehchors ${ }^{\mathrm{a}, \mathrm{b}}$, Viet Huong Nguyen ${ }^{\mathrm{c}, \mathrm{d}}$, David Muñoz-Rojas ${ }^{\mathrm{a},}{ }^{,}$, Carmen Jiménez ${ }^{\mathrm{a}}$, Laetitia Rapenne $^{a}$, Ngoc Duy Nguyen ${ }^{b}$, Daniel Bellet ${ }^{a, *}$

Silver nanowire (AgNW) networks have been lately much investigated thanks to their physical properties and are therefore foreseen to play a key role in many industrial devices as transparent electrodes, but their stability can be an issue. Although it has been shown that thin metal oxide coatings enhance the stability of AgNW networks, such stabilization is achieved at the expenses of transparency. We demonstrate that by depositing a second oxide coating, which acts as an antireflective layer, it is possible to obtain highly stable and transparent composite electrodes. AgNW networks were deposited by the airbrush method, and zinc oxide $(\mathrm{ZnO})$ and aluminum oxide $\left(\mathrm{Al}_{2} \mathrm{O}_{3}\right)$ coatings were deposited, by Atmospheric Pressure Spatial Atomic Layer Deposition (AP-SALD), using both glass and plastic substrates: therefore the proposed fabrication method is low-cost and compatible with high-throughput scalable fabrication. The mechanical stability of bare, $\mathrm{ZnO}$ and $\mathrm{ZnO} / \mathrm{Al}_{2} \mathrm{O}_{3}-$ coated AgNWs upon bending is also presented. The obtained nanocomposites exhibit highly homogeneous and conformal oxide coatings with average thicknesses of a few tens of nanometers. Samples with bilayer coating of $70 \mathrm{~nm} \mathrm{ZnO} / 70 \mathrm{~nm}$ $\mathrm{Al}_{2} \mathrm{O}_{3}$ still exhibit very good stability after annealing in air up to $450{ }^{\circ} \mathrm{C}$ for 6 repetitive cycles.
\end{abstract}

\section{Introduction}

Transparent electrodes (TEs) have a wide range of applications in many modern optoelectronic devices, such as organic lightemitting diodes (OLEDs), touch screens, solar cells, e-papers, transparent heaters, and sensors. ${ }^{1}$ Wide bandgap conductive metal oxides like Indium Tin Oxide (ITO) have been the most successfully commercialized transparent conductive material to date. ITO shows outstanding electrical and optical properties, sheet resistance below $10 \Omega \mathrm{sq}^{-1}$ and total transmittance about $90 \%$ at $550 \mathrm{~nm}^{2}$ Despite these interesting properties, there has been extensive research in the last years to introduce alternative materials to replace ITO. The scarcity of indium, together with the vacuum based expensive fabrication methods like sputtering and the lack of mechanical flexibility of ITO, are the main reasons behind this urge to replace it with new candidates. ${ }^{3}$ Several potential emerging materials include random networks of metallic nanowires, conductive polymers or carbon-based materials like Carbon Nano Tubes (CNTs) or Graphene. 3,4 In particular, percolative networks composed of high aspect ratio metallic nanowires (MNW) are promising candidates among these emerging materials. ${ }^{5-7} \mathrm{MNW}$ networks

a. Univ. Grenoble Alpes, CNRS, Grenoble INP, LMGP, F-38000 Grenoble, France b. 2 Département de Physique, Université de Liège, CESAM/Q-MAT, SPIN, B-4000 Liège, Belgium

c. Faculty of Electrical and Electronic Engineering, Phenikaa University, Hanoi 12116, Vietnam

d. Phenikaa Research and Technology Institute (PRATI), A\&A Green Phoenix Group JSC, No.167 Hoang Ngan, Trung Hoa, Cau Giay, Hanoi 11313, Vietnam

+Corresponding authors: david.munoz-rojas@grenoble-inp.fr; daniel.bellet@grenobleinp.fr

Electronic Supplementary Information (ESI) available: [details of any supplementary information available should be included here]. See DOI: 10.1039/x0xx00000x exhibit excellent electro-optical properties comparable to ITO, along with high mechanical flexibility. ${ }^{8}$ In addition, the consumption of metal is much reduced in these MNW based electrodes as compared to the required indium in ITO electrodes to obtain similar properties. AgNW based networks with areal mass density around 100 to $200 \mathrm{mg} / \mathrm{m}^{2}$ show electrical sheet resistance below $5 \Omega \mathrm{sq}^{-1}$ and total transmittance around $89 \%$ at $550 \mathrm{~nm},{ }^{9}$ while for ITO films with thickness of $150 \mathrm{~nm}$ and similar electro-optical properties, indium areal mass density is around $900 \mathrm{mg} / \mathrm{m}^{2}{ }^{10}$ Random networks of various metallic nanowires (mainly silver, copper or cupronickel) can be deposited using vacuum-free, low-cost and scalable solution-based techniques ${ }^{11,12}$ on numerous types of substrates. ${ }^{13-15}$ Among the different MNW networks, the ones based on AgNWs appear so far to be the most attractive candidate thanks to the simple synthesis of AgNWs and since they meet the required electro-optical properties for many applications, due to the high electrical conductivity of silver. But, despite the mentioned attractive characteristics of AgNW based TEs, there are still some limitations which prevent a rapid integration of these electrodes into functional commercial devices. For example, as-deposited AgNW networks tend to show very poor adhesion to the substrate. Besides, there is a lack of stability in the ambient conditions and such electrodes present instability when subjected to thermal and/or electrical stresses. Such an instability can derive from atomic diffusion of silver, ${ }^{14,16}$ electromigration processes resulting from high current density ${ }^{17,18}$ or oxidation/sulphurization of silver when the networks are placed in high humidity and/or hightemperature environments. ${ }^{19-21}$ One efficient way to hinder these instabilities has been to protect the AgNW networks with thin layers (tens of $\mathrm{nm}$ ) of metallic oxides like Zinc Oxide (ZnO), ${ }^{22-24}$ Aluminum doped Zinc Oxide (Al:ZnO), ${ }^{25,26}$ Titanium dioxide $\left(\mathrm{TiO}_{2}\right)^{27}$ or Aluminum oxide $\left(\mathrm{Al}_{2} \mathrm{O}_{3}\right)^{24,28}$ which have 
shown to provide a clear enhancement of the stability of AgNW networks. So far sol-gel, ${ }^{27,29}$ sputtering, ${ }^{23,26}$ spin coating, ${ }^{30,31}$ and atomic layer deposition (ALD) ${ }^{32}$ have been used to deposit metal oxide coatings over AgNW networks. Although the composite layers fabricated using these methods showed much higher stability as compared to the un-coated AgNW networks, some characteristics of the used deposition methods, such as either the requirement of vacuum, low deposition rate or the low scalability, are in contrast with one of the main advantages of AgNW based TEs, which is low-cost and high-throughput scalable fabrication. In a previous article, we have shown that atmospheric pressure spatial atomic layer deposition (AP-SALD) is a very appealing technique to engineer stable AgNW electrodes, $^{22}$ since it shares the main advantages of ALD (conformal and homogeneous oxide films with a precise control of the thickness deposited), while being up to two orders of magnitude faster than conventional ALD and more suitable for scaling up. ${ }^{33}$ An open air AP-SALD was thus used to deposit $\mathrm{ZnO}^{22}$ or aluminium-doped $\mathrm{ZnO}^{34}$ thin layers to improve the thermal and electrical stability of AgNW networks. Nevertheless, the enhanced stability of the composites was obtained at the expense of transparency due to both reflection and absorption of the $\mathrm{ZnO}$ layer. ${ }^{22}$ In this work, the possibility of depositing $\mathrm{Al}_{2} \mathrm{O}_{3}$ by $\mathrm{AP}$-SALD as a protective layer and its comparison to $\mathrm{ZnO}$ in terms of thermal stability, optical transparency and reproducibility is investigated. Our results show that, while the $\mathrm{ZnO}$-coated AgNW networks present irreversible changes of the electrical resistance above $280{ }^{\circ} \mathrm{C}$, $\mathrm{Al}_{2} \mathrm{O}_{3}$-coated networks do not show any sign of stability loss when subjected to temperatures up to $380{ }^{\circ} \mathrm{C}$. In addition, although the bare networks show the highest average transparency in the visible wavelength range, from 380 to 700 $\mathrm{nm},(85 \%)$, the transparency of $\mathrm{Al}_{2} \mathrm{O}_{3}$-coated networks (80\%) was higher than for those coated with $\mathrm{ZnO}(73 \%)$, with the same coating thickness of $50 \mathrm{~nm}$. Nevertheless, the difference in thermal expansion coefficients between $\mathrm{Al}_{2} \mathrm{O}_{3}$ thin film and glass substrate caused partial delamination of the electrodes at elevated temperatures, this delamination leads to nonperfectly reproducible $\mathrm{Al}_{2} \mathrm{O}_{3}$-coated $\mathrm{AgNW}$ networks. Here we present composite electrodes in which the $\mathrm{AgNW}$ networks were coated by a $\mathrm{ZnO} / \mathrm{Al}_{2} \mathrm{O}_{3}$ bilayer coating. As a result, up to a $10 \%$ enhancement in optical transmittance of $\mathrm{ZnO} / \mathrm{Al}_{2} \mathrm{O}_{3}-$ coated AgNWs networks was obtained when compared to $\mathrm{ZnO}$ coated ones. As discussed below this is due to an antireflective effect of the $\mathrm{Al}_{2} \mathrm{O}_{3}$ coating. In addition, thanks to the possibility of using thick metal oxide coatings while not having a detrimental effect on transmittance, the bilayer coatings confer a substantial enhancement in thermal stability, and therefore such electrodes have the potential to be embedded in functional devices with a much improved lifetime. Finally, we examined the mechanical stability of $\mathrm{ZnO}$ and $\mathrm{ZnO} / \mathrm{Al}_{2} \mathrm{O}_{3}$-coated AgNW based TEs, and the results confirm that such composite electrodes clearly possess a much higher mechanical stability than ITO based transparent electrodes for optimized coatings.

\section{Methods and experimental conditions}

\subsection{Deposition of AgNW networks}

AgNWs with an average diameter of $90 \mathrm{~nm}$ and lengths between 10 to $20 \mu \mathrm{m}$ were purchased from ACS material, and dispersed in isopropyl alcohol (IPA) with an initial concentration of $20 \mathrm{mg} / \mathrm{mL}$. This suspension was used to prepare diluted suspensions of $0.1 \mathrm{mg} / \mathrm{mL}$ by adding IPA. A 30 second-long sonication process was performed to homogeneously disperse AgNWs prior to dilution. Corning alkaline glasses from Delta Technologies and Neopulim from MGCMINC were used as substrates. Glass substrates were cleaned in a three-step process: sonication in acetone, followed by sonication in ethanol then rinsing by deionized water and drying using a $\mathrm{N}_{2}$ flow to remove any possible contamination on the substrates prior to deposition. Neopulim films were exposed to an oxygen plasma treatment for 90 seconds in order to increase their hydrophilicity, and thus to enhance the wettability of the AgNW suspensions over the substrate so that homogeneous coatings could be obtained.

Spin coating and spray deposition techniques were both used to fabricate AgNW networks. Spin coating was performed by deposition of $1 \mathrm{~mL}$ of AgNW solution onto the rotating substrate (1500 rpm) in pulses of about 1 drop per second, and in two stages of $0.5 \mathrm{~mL}$ each with a 30 seconds pause between them, allowing the surface to dry. An airbrush (Harder \& Steenbeck) was used to spray the AgNW networks. The following parameters were used for the deposition: nozzle diameter was $0.15 \mathrm{~mm}$, pressure of $\mathrm{N}_{2}$ as carrier gas was fixed at 3 bars, flow rate of solvent was kept around $0.2 \mathrm{~mL} / \mathrm{min}$ and the airbrush nozzle was fixed at the height of $10 \mathrm{~cm}$ above the substrate. The substrates were heated up to $90{ }^{\circ} \mathrm{C}$ during deposition in order to facilitate fast evaporation of the solvent. Spin coating is known to induce a preferential orientation of AgNWs due to the centrifugal forces, while a spray-based technique (used for the bare and $\mathrm{ZnO}$-coated specimens) provides more randomly oriented AgNW deposition. ${ }^{35}$ The effect of preferential orientation of AgNWs on the network percolation threshold, therefore on the network resistance, has been discussed by Langley et al. ${ }^{36}$ In this paper both methods were used for AgNW network fabrication and the same main conclusions appear valid for both method. After the deposition, a thermal annealing in air at $230{ }^{\circ} \mathrm{C}$ for one hour was performed to improve the electrical conductivity of networks by sintering the junction between nanowires. All thermal treatments related to the present work were performed in air. Thin silver film contacts (50 $\mathrm{nm}$ thick) were deposited at the edges of the electrodes using an Edwards Auto 306 thermal evaporator. Optimized spray-coated networks had a sheet resistance of $5.9 \Omega \mathrm{sq}^{-1}$ and an optical transmittance of $84.3 \%$ at $550 \mathrm{~nm}$, and values for Haack's figure of merit were around $30 \times 10^{-3} \Omega^{-1}$.

\subsection{Deposition of $\mathrm{ZnO}$ and $\mathrm{Al}_{2} \mathrm{O}_{3}$ coatings by AP-SALD}

The deposition of $\mathrm{ZnO}$ and $\mathrm{Al}_{2} \mathrm{O}_{3}$ films was performed with a home-made atmospheric pressure spatial atomic layer deposition (AP-SALD) system. ${ }^{37}$ In our AP-SALD system, the precursors are continuously injected on the moving substrate 

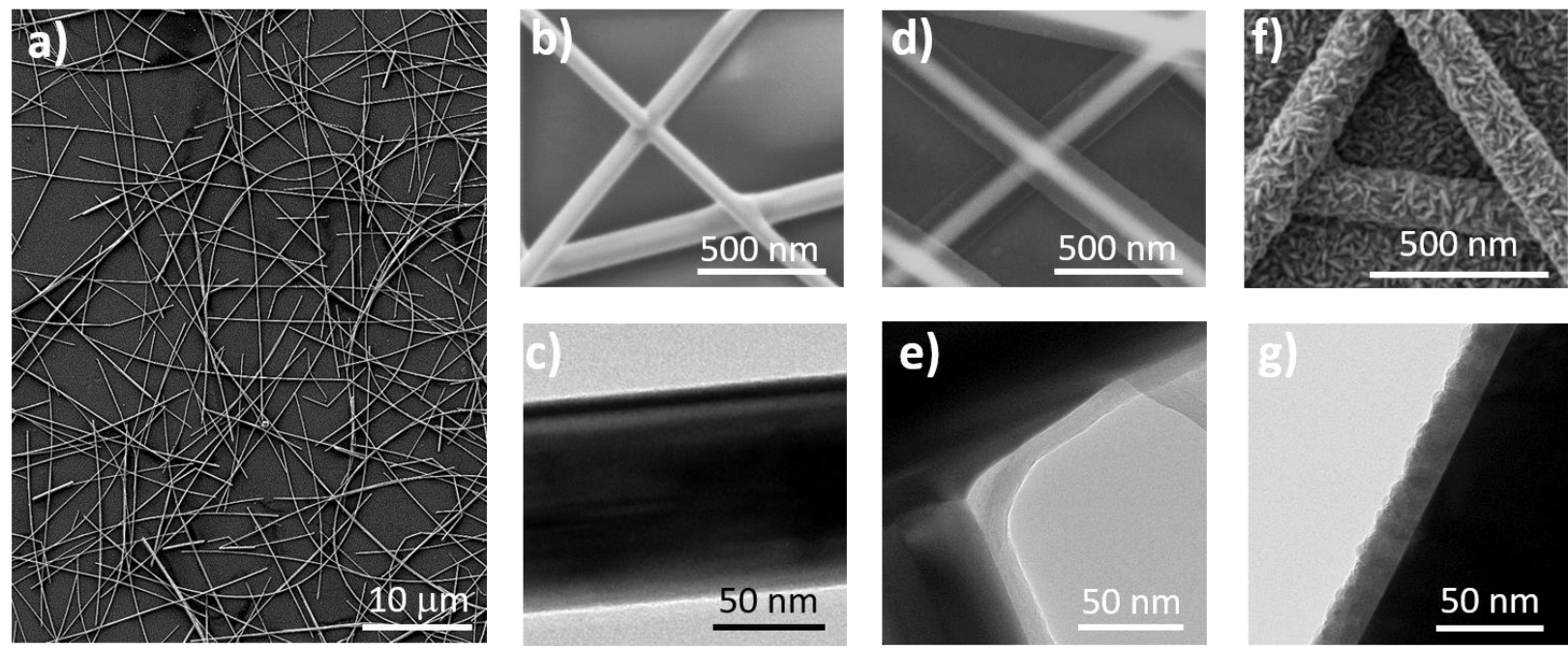

Figure 1. (a) SEM image of a AgNW network deposited by spray coating. (b) High magnification SEM image of a bare AgNW network revealing the efficient sintered junctions. (c) TEM image of a bare AgNW with average diameter of $90 \mathrm{~nm}$. (d) SEM image of an $\mathrm{Al}_{2} \mathrm{O}_{3}$-coated AgNW network with an average coating thickness of around $60 \mathrm{~nm}$. (e) TEM image of a $10 \mathrm{~nm}$ thick $\mathrm{Al}_{2} \mathrm{O}_{3}$-coated $\mathrm{AgNW}$, showing the conformal and amorphous nature of the $A P-S A L D ~ A l_{2} \mathrm{O}_{3}$ coating. (f) SEM image of a ZnO-coated AgNW with an average coating thickness of around $40 \mathrm{~nm}$. (g) TEM image of a $15 \mathrm{~nm}$ thick ZnO-coated AgNW, showing the polycrystalline nature of the AP-SALD ZnO layer.

from different locations of a fixed gas injector, as shown schematically in Fig. SI-1 in the Supplementary Information.

In this design, the reactive precursors are spatially separated thanks to inert gas barriers located alternatively between precursor flows. The oscillating substrate is at a constant and very short distances $(50 \mu \mathrm{m}-300 \mu \mathrm{m})$ from the fixed gas injector, making gas separation effective and replicating conventional ALD cycles. In this work, trimethylaluminum (TMA, $\left.\mathrm{Al}\left(\mathrm{CH}_{3}\right)_{3}\right)$, diethylzinc $\left(\mathrm{DEZ}, \mathrm{Zn}\left(\mathrm{C}_{2} \mathrm{H}_{5}\right)_{2}\right)$ and water $\left(\mathrm{H}_{2} \mathrm{O}\right)$ were used as precursors for aluminum, zinc and oxygen, respectively. The deposition temperature was set at $150{ }^{\circ} \mathrm{C}$ for $\mathrm{Al}_{2} \mathrm{O}_{3}$ and 200 ${ }^{\circ} \mathrm{C}$ for $\mathrm{ZnO}$. The samples were maintained at a distance of 200 $\mu \mathrm{m}$ from the gas injector, and oscillated at a maximum speed of $5 \mathrm{~cm} / \mathrm{s}$. The thickness of coatings is proportional to the number of AP-SALD cycles performed, with a growth rate of about 0.15 $\mathrm{nm} /$ cycle for $\mathrm{Al}_{2} \mathrm{O}_{3}$ and $0.25 \mathrm{~nm} /$ cycle for $\mathrm{ZnO}$. The thickness of the metal oxide layers were determined thanks to the SEM observations since the growth conditions were identical to the nanocomposites for which the optical properties and stability were studied in the article.

\subsection{Morphological and optical characterizations}

A lambda 950 UV/Visible/NIR Spectrophotometer from Perkin Elmer with an integrating sphere was used to measure transmittance of the different samples in the wavelength range from 250 to $2500 \mathrm{~nm}$. Measurements were repeated on several parts of each sample and average values were reported.

Scanning Electron Microscopy (SEM) images were obtained with a field-emission gun (FEG) SEM Environmental FEI QUANTA 250 using an accelerating voltage of $10 \mathrm{keV}$. Transmission electron microscopy (TEM) images were obtained using a JEOL 2010 LaB6 microscope operating at $200 \mathrm{kV}$ with a $0.19 \mathrm{~nm}$ pointto-point resolution. $\mathrm{AgNWs}$ and $\mathrm{ZnO} / \mathrm{Al}_{2} \mathrm{O}_{3}$ coatings were directly deposited on carbon coated copper grids for TEM observations.

\section{4 Thermal and mechanical stability studies}

A two-probe setup controlled with a Keithley 2400 sourcemeter was used to perform in situ measurements of the network electrical resistance during either thermal or mechanical cycles. The networks were heated in air up to $450^{\circ} \mathrm{C}$ at a rate of $2^{\circ} \mathrm{C} /$ min to study their thermal evolution. The thermal stability of AgNW networks is critical regardless that the network is deposited on flexible polymeric substrates or on glass. The use of high temperatures in this work could be seen as an accelerated damaging process for which the comparison between different coatings is of importance. Mechanical stability was investigated in bending mode on bare and coated AgNW networks deposited on Neopulim substrates with a bending radius of $5 \mathrm{~mm}$ using a home-made setup.

\section{Results and Discussions}

\section{3. $1 \mathrm{ZnO}$ and $\mathrm{Al}_{2} \mathrm{O}_{3}$ coatings on AgNW networks by AP-SALD}

In order to explore the morphology of the bare and coated networks, SEM and TEM studies were performed. Fig. 1a presents a SEM image of a bare AgNW network on glass after deposition and annealing in air at $230^{\circ} \mathrm{C}$ for one hour. As shown in the image, spray deposition results in homogeneous and random AgNW networks over the substrate. A close-up in Fig. $1 \mathrm{~b}$ shows an example of a clear sintering of the junctions as a result of thermal annealing. An example of TEM images is presented in Fig. 1c, which confirms that the average diameter of AgNWs is around $90 \mathrm{~nm}$. Fig. $1 \mathrm{~d}$ presents a SEM close-up of a network coated with $60 \mathrm{~nm}$ of $\mathrm{Al}_{2} \mathrm{O}_{3}$, where a homogeneous and 
conformal oxide coating over the AgNW network and glass substrate can be clearly observed. This is so even for very thin coatings, as for example the $10 \mathrm{~nm} \mathrm{Al}_{2} \mathrm{O}_{3}$ coating shown in Fig. 1 e. Such quality of the oxide film is crucial since any crack or non-uniformity in the coating can be detrimental to the network stability. ${ }^{22}$ Since the deposition of $\mathrm{Al}_{2} \mathrm{O}_{3}$ is performed at $150{ }^{\circ} \mathrm{C}$, which is low compared to the crystallization temperature of $\mathrm{Al}_{2} \mathrm{O}_{3}$ (around $\left.800{ }^{\circ} \mathrm{C}\right)^{38}$, amorphous coatings were obtained in our study. Energy Dispersive X-Ray Spectroscopy (EDS) confirmed the presence of $\mathrm{Al}$ and $\mathrm{O}$ in the coating area (the corresponding images can be found in Fig. $\mathrm{SI}-2$ in the Supplementary Information). Fig. If and $1 \mathrm{~g}$ show examples of SEM and TEM images of AgNW networks with $50 \mathrm{~nm}$ and $15 \mathrm{~nm}$ of $\mathrm{ZnO}$ coatings, respectively. As for $\mathrm{Al}_{2} \mathrm{O}_{3}$ coatings, the TEM images clearly show the conformality, compactness and homogeneity of the coating. In this case, crystalline $\mathrm{ZnO}$ is obtained, and the polycrystalline morphology of the $\mathrm{ZnO}$ coatings can be clearly seen. Fig. 1.f exhibits a SEM image with $40 \mathrm{~nm}$ of $\mathrm{ZnO}$ coating which clearly reveals that $\mathrm{ZnO}$ is coated on both AgNWs and substrate, the latter coating being at the origin of the optical transmission decrease. While not obvious on other shown SEM pictures this observation is similar for all specimen.

\section{2 Effect of $\mathrm{ZnO}$ and $\mathrm{Al}_{2} \mathrm{O}_{3}$ coatings on the thermal stability of AgNW networks}

The stability of AgNW networks against thermal stress is a critical point in the integration of TEs based on AgNW networks in different applications, in particular when used as transparent heaters. ${ }^{29,39}$ The degradation of the network due to a temperature rise can produce irreversible changes in the network morphology due to surface diffusion, leading to a nonreversible increase of the network electrical resistance. ${ }^{39}$

a)

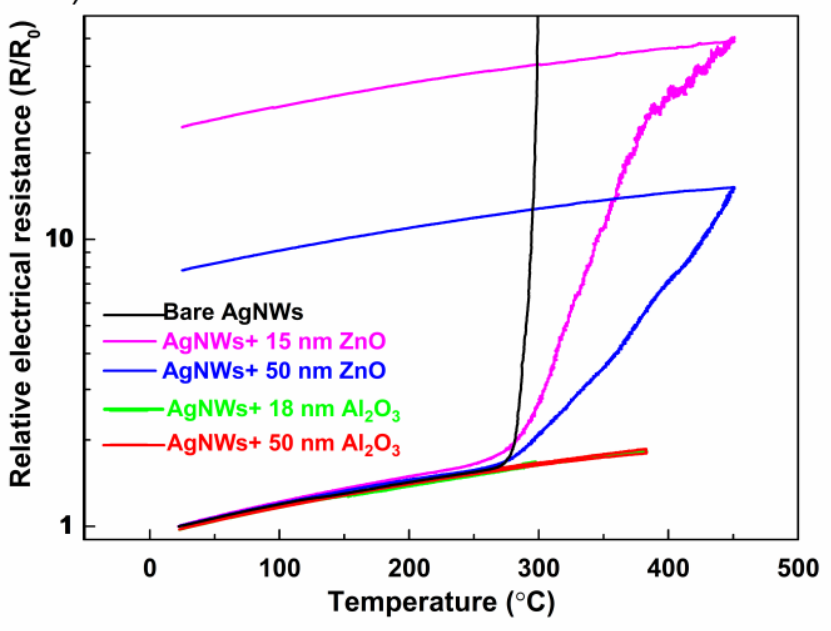

Here we have compared the evolution of electrical resistance of bare, $\mathrm{ZnO}$ and $\mathrm{Al}_{2} \mathrm{O}_{3}$-coated $\mathrm{AgNW}$ networks during thermal ramps in air from room temperature to over $400^{\circ} \mathrm{C}$ with a ramp rate of $2{ }^{\circ} \mathrm{C} \mathrm{min}-1$. As presented in Fig. 2-a, an increase of temperature from room temperature to around $250^{\circ} \mathrm{C}$, implies an increase in the electrical resistance for both bare and coated AgNW networks. This typical behaviour for metallic materials can be attributed to electron-phonon interactions. ${ }^{38} \mathrm{~A}$ linear approximation can be used to model the dependency of electrical resistivity $\rho$ versus temperature $T$ as:

$\rho\left(T_{0}+\Delta T\right)=\rho_{0}(T) \times\left(1+\beta_{R} \Delta T\right)$

where $\rho_{0}$ is the electrical resistivity at the temperature $T_{0}$ while $\beta_{R}$ is the temperature coefficient of resistivity. For bare AgNW networks $\beta_{R}$ is around $(2.4 \pm 0.1) \times 10^{-3} \mathrm{~K}^{-1}$, while it is $(2.6 \pm 0.1) \times 10^{-3} \mathrm{~K}^{-1}$ and $(2.3 \pm 0.1) \times 10^{-3} \mathrm{~K}^{-1}$ for $\mathrm{ZnO}$ and $\mathrm{Al}_{2} \mathrm{O}_{3}{ }^{-}$ coated AgNW networks, respectively. Such values are very close to that reported for AgNW networks by Lagrange et al. ${ }^{9}$ $\left((2.4 \pm 0.1) \times 10^{-3} \mathrm{~K}^{-1}\right)$. When compared with $\beta_{R}$ for bulk silver, $3.8 \times 10^{-3} \mathrm{~K}^{-1},{ }^{40}$ the $\beta_{R}$ value for AgNW networks appears to be much smaller, probably due to surface effects within AgNWs, the presence of junctions between different AgNWs and possible defects such as grain boundaries or twins for instance. After the linear increase of resistance, bare AgNW networks undergo the well-known Plateau-Rayleigh instability around $300{ }^{\circ} \mathrm{C}$, with the consequent sudden increase in the electrical resistance of the network. ${ }^{9,14}$ This phenomenon occurs thanks to the surface diffusion of $\mathrm{Ag}$ atoms, the associated driving force being the decrease of the total surface energy. This shape shifting effect is called spheroidization. Metal oxide coatings act as barriers for Ag atoms as they hinder the diffusion process. As a result, unlike bare networks, ZnO-coated AgNW networks remain conductive after a full thermal ramp up to $450{ }^{\circ} \mathrm{C}$, as shown by Fig. 2-a. The dependency of the stability

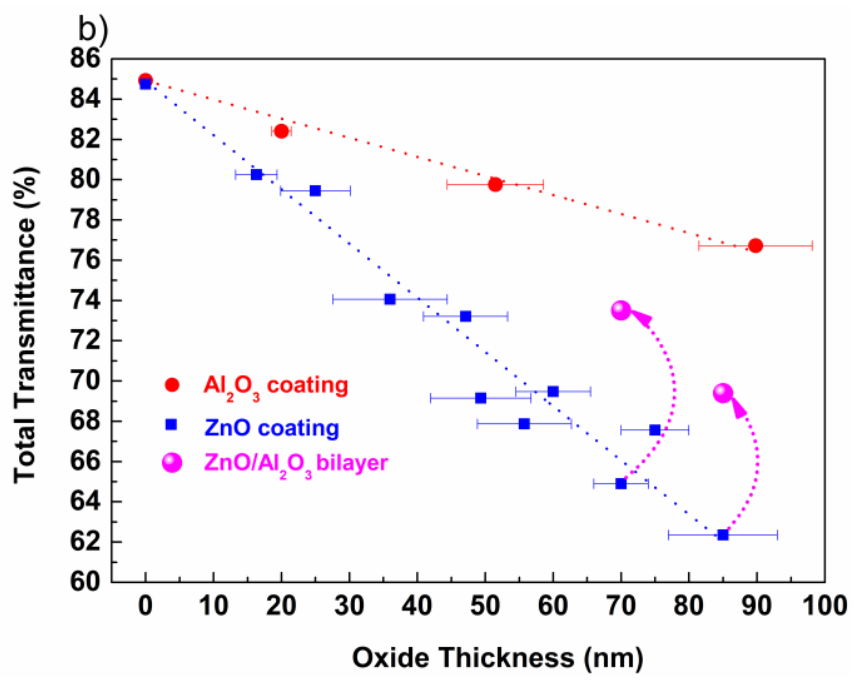

Figure 2. (a) In situ measured relative resistance $\left(\mathrm{R} / \mathrm{R}_{0}\right)$ of bare, $\mathrm{ZnO}$ and $\mathrm{Al}_{2} \mathrm{O}_{3}$-coated $\mathrm{AgNW}$ networks with a thermal annealing in air with a ramp of $2^{\circ} \mathrm{C}$ $\mathrm{min}^{-1}$. This clearly shows the crucial role played by the oxide layer coating as well as the effect of its thickness. (b) Average total transmittance of $\mathrm{Al}_{2} \mathrm{O}_{3}$, $\mathrm{ZnO}$ and $\mathrm{ZnO} / \mathrm{Al}_{2} \mathrm{O}_{3}$-coated $\mathrm{AgNW}$ networks in the visible wavelength range, from 380 to 700 nm, versus oxide thickness, this shows that $\mathrm{Al}_{2} \mathrm{O}_{3}$ coatings induce smaller losses in optical transmittance as compared to $\mathrm{ZnO}$ coatings. Two examples at $70 \mathrm{~nm}$ and $85 \mathrm{~nm}$ confirm antireflective effect of $\mathrm{Al}_{2} \mathrm{O}_{3}$ coating over $\mathrm{ZnO}$ layer. 
enhancement on the $\mathrm{ZnO}$ coating thickness was investigated in our previous study, in which we demonstrated that thicker coating leads to better stability. ${ }^{22} \mathrm{~A}$ diffusion model of $\mathrm{Ag}$ atoms through $\mathrm{ZnO}$ coating was proposed to rationalize this dependency. ${ }^{22}$ If the $\mathrm{ZnO}$ barrier is not efficient enough, then silver atoms can diffuse through the oxide coating leading to hollow shells solely composed of the oxide layer. An example of such diffusion process effect is shown in Fig. SI-3 in the Supplementary Information, where an AgNW network with 45 $\mathrm{nm}$ of $\mathrm{ZnO}$ coating was annealed in air at $400{ }^{\circ} \mathrm{C}$ for 30 minutes. Unlike for bare or $\mathrm{ZnO}$-coated AgNWs, there is no irreversible change in the electrical resistance of $\mathrm{Al}_{2} \mathrm{O}_{3}$-coated $\mathrm{AgNW}$ networks after the similar annealing cycle, as shown by Fig. 2a. For the networks coated with $18 \mathrm{~nm}$ and $50 \mathrm{~nm}$ of $\mathrm{Al}_{2} \mathrm{O}_{3}$ we observe linear dependency of the electrical resistance with temperature while heating electrodes up to $380^{\circ} \mathrm{C}$ and cooling down to room temperature. As for the case of $\mathrm{ZnO}$ coatings, the drastic improvement in thermal stability of $\mathrm{Al}_{2} \mathrm{O}_{3}$-coated networks comes also at the expense of the total transmittance. However in the case of $\mathrm{Al}_{2} \mathrm{O}_{3}$, the loss in transparency is less important than for networks coated with $\mathrm{ZnO}$, due to the wider bandgap of $\mathrm{Al}_{2} \mathrm{O}_{3}$ with respect to $\mathrm{ZnO}$ ( $8 \mathrm{eV}$ versus $3.3 \mathrm{eV}$, respectively). ${ }^{37,41,42}$ This is shown in Fig. $2 \mathrm{~b}$ which represents the total transmittance of $\mathrm{ZnO}$ and $\mathrm{Al}_{2} \mathrm{O}_{3}$-coated $\mathrm{AgNW}$ networks as a function of oxide thickness. A $50 \mathrm{~nm}$ thick $\mathrm{ZnO}$ coating reduces the average total transmittance in the visible range (from 380 to $700 \mathrm{~nm}$ ) from $85 \%$ for bare AgNWs to $73 \%$, while for the same thickness range of $\mathrm{Al}_{2} \mathrm{O}_{3}$ the total transmittance varies from $85 \%$ to $80 \%$. The values of oxide thickness reported in Fig. $2 \mathrm{a}$ and Fig. $2 \mathrm{~b}$, are based on cross-sectional SEM images which were performed on different areas for each sample.

The wide band gap of $\mathrm{Al}_{2} \mathrm{O}_{3}$ has the advantage of lowering optical loss when compared with $\mathrm{ZnO}$, which should be of great help in applications such as transparent heaters. However it can be a bit too restrictive for some of the applications where very good electrical conductivity along the substrate plane is required such as for collection or injection of charges. Such a requirement concerns for instance the front electrode of thin film solar cells, where composite electrodes made with $\mathrm{ZnO}$ coatings and AgNW networks proved to increase the device efficiency, as compared to the bare AgNWs, thanks to an improved charge collection efficiency. ${ }^{23} \mathrm{~A}$ way to mitigate the partial hindering of the photo-generated carriers through the non-conductive $\mathrm{Al}_{2} \mathrm{O}_{3}$ layer could be to proceed with the $\mathrm{ZnO}$ SALD coating first, then the metallization with the external electrical contacts and eventually the $\mathrm{Al}_{2} \mathrm{O}_{3}$ coating used as antireflective coating and diffusive barrier. Thanks to the chemical conformal coating associated to the SALD technique such a configuration should be well adapted for an efficient integration. Another important difference to note between $\mathrm{Al}_{2} \mathrm{O}_{3}$ and $\mathrm{ZnO}$ coatings is their different thermal expansion coefficient. The $\mathrm{Al}_{2} \mathrm{O}_{3}$ films deposited by ALD have a coefficient of $4.2 \times 10^{-6} \mathrm{~K}^{-1}, 43$ while a coefficient of $15.7 \times 10^{-6} \mathrm{~K}^{-1}$ was measured for ALD ZnO coatings ${ }^{44}$ (with the wurtzite structure). For the glass substrates thermal expansion coefficient is reported around $9 \times 10^{-6} \mathrm{~K}^{-1}$. Thus, as a result of the mismatch in the thermal expansion coefficients, $\mathrm{Al}_{2} \mathrm{O}_{3}$ coatings might not be able to follow the thermal expansion of glass substrate at high temperatures, which can lead to breaking and/or delamination of the AgNWs $/ \mathrm{Al}_{2} \mathrm{O}_{3}$ composites. This is indeed what we did observe, an example of such delamination is shown in Fig. SI-4 in the Supplementary Information. It is worth to mention that since AgNWs are very flexible ${ }^{7}$ and can follow buckling as a result of high temperature, they are unlikely to be the origin of delamination process. Following these two arguments we have investigated the effects of $\mathrm{ZnO} / \mathrm{Al}_{2} \mathrm{O}_{3}$ bilayer coatings.

\section{3 Antireflective properties of $\mathrm{ZnO} / \mathrm{Al}_{2} \mathrm{O}_{3}$ bilayer coatings on AgNW networks}

As stated above, the optical loss caused by ZnO layer can be due to light absorption or reflection. The latter stems from the difference in the refractive index of the media in which light propagates. Antireflective coatings are one of the basic elements in optical systems and can improve the multi-layer's transmittance by reducing the surface reflection. $\mathrm{Al}_{2} \mathrm{O}_{3}$ has been successfully used as antireflective coating on $\mathrm{ZnO}$ layers in thin film devices. ${ }^{45,46}$ We have applied the same principle aiming to obtain oxide layers on top of AgNW networks which enhance the network's stability (thanks to $\mathrm{ZnO}$ layer) while retaining a high transmittance (thanks to $\mathrm{Al}_{2} \mathrm{O}_{3}$ layer). Fig. 3a and $3 \mathrm{~b}$ present, respectively, TEM and cross-sectional SEM images of bilayer coatings of $\mathrm{ZnO} / \mathrm{Al}_{2} \mathrm{O}_{3}$ on AgNWs. Estimated thickness of each oxide is around $50 \mathrm{~nm}$ in TEM image and $70 \pm 3 \mathrm{~nm}$ in SEM image while the identical AP-SALD process was used in both cases. The difference in the thickness values stems mainly from the different growth rate on copper grids (used for TEM samples) and Corning glass (used for SEM samples).

Several $\mathrm{ZnO}$ and $\mathrm{Al}_{2} \mathrm{O}_{3}$ thicknesses were selected for experimental observations. The thickness of each layer was chosen for a proof of concept of the anti-reflecting coating effect. A well-adapted application for optimizing in first approximation the thickness of $\mathrm{ZnO}$ and $\mathrm{Al}_{2} \mathrm{O}_{3}$ layers is for the integration of the nanocomposite as the front transparent electrode of a photovoltaic solar cell, which requires to minimize reflection losses. For such a task one can use the analytical optical equations which are detailed in the Supplementary Information (part 7). The obtained results discussed in SI have been used to test experimentally the $\mathrm{ZnO} / \mathrm{Al}_{2} \mathrm{O}_{3}$ bilayer coatings which exhibit the most promising anti-reflective effect. For instance, the combination of thicknesses of $70 \mathrm{~nm} / 70 \mathrm{~nm}$ for the $\mathrm{ZnO} / \mathrm{Al}_{2} \mathrm{O}_{3}$ bilayer coating appears pertinent and then was experimentally investigated. However, this is worth noticing that while the optical simulation can be considered as a useful but basic guide for the proof of concept of the anti-reflective coating, the detailed optical properties of the real thin layers are indeed dependent on the growth method and experimental conditions. A thorough comparison between experimental data and simulations would be needed to obtain more accurate predictions. However we consider that such a task is out of the scope of this article. Prior the deposition of the bilayers on AgNW networks, optical measurements were performed on Corning glass substrates to confirm the occurrence of an antireflective effect. For instance, 
a)

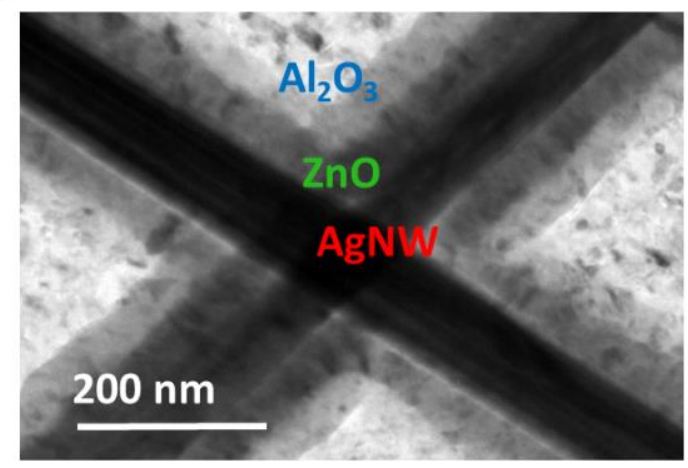

c)

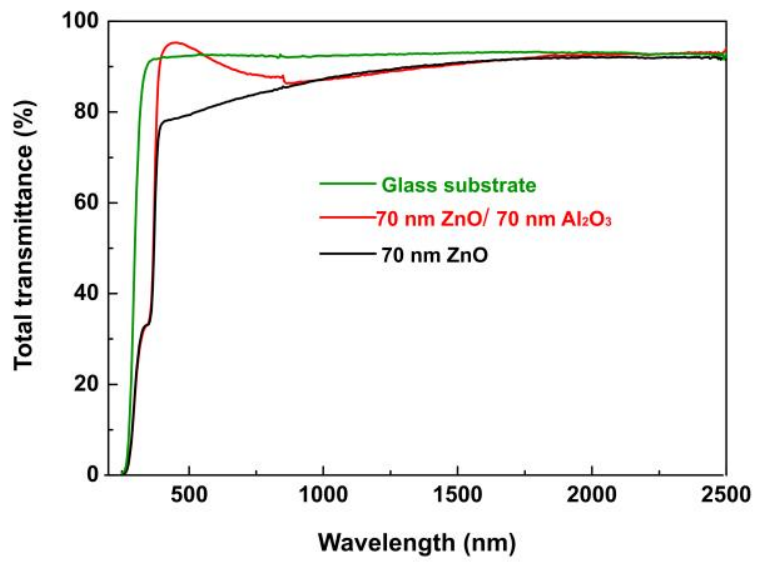

b)

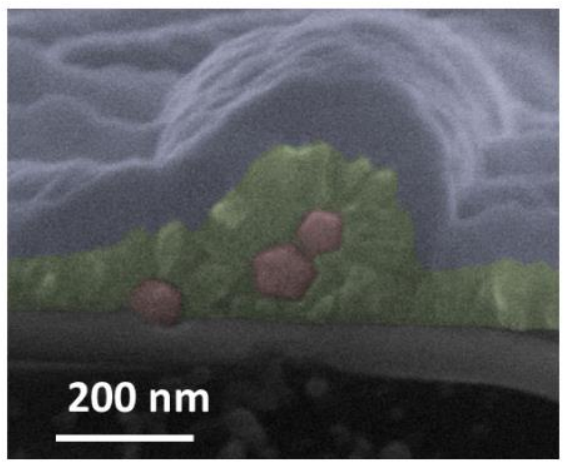

d)

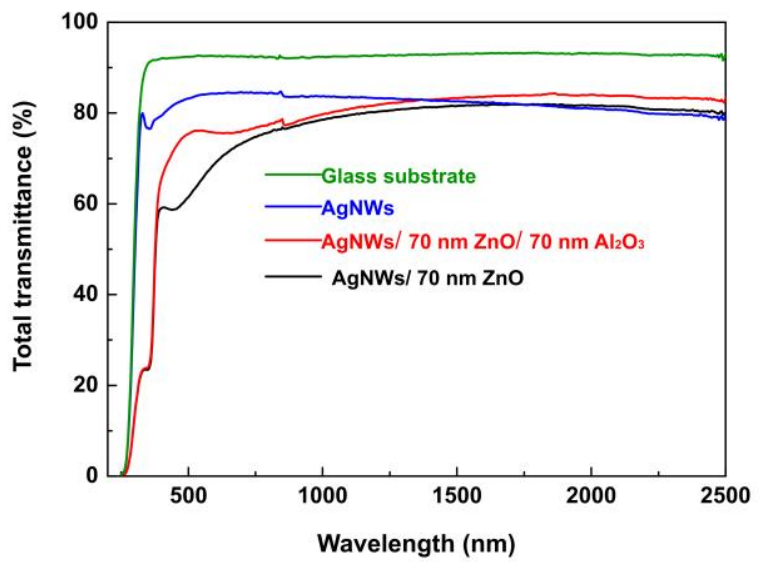

Figure 3. (a) TEM image of a junction between two AgNWs with a coating composed of $50 \mathrm{~nm} \mathrm{Al}_{2} \mathrm{O}_{3}$ on top of $50 \mathrm{~nm} \mathrm{ZnO}$. (b) Cross sectional $\mathrm{SEM}$ image of bilayer coatings of $70 \mathrm{~nm} \mathrm{ZnO/70} \mathrm{nm} \mathrm{Al} \mathrm{O}_{3}$ deposited on AgNWs. The SEM image has been colored for the sake of clarity. (c) Total transmittance of the $70 \mathrm{~nm}$ ZnO film deposited on bare glass and antireflective $70 \mathrm{~nm} \mathrm{ZnO} / 70 \mathrm{~nm} \mathrm{Al}_{2} \mathrm{O}_{3}$ deposited on bare glass ( $\mathrm{ZnO}$ being first deposited). (d) Total transmittance of the AgNW networks, 70 nm thick ZnO film coating AgNW networks and AgNW network coated with the antireflective $70 \mathrm{~nm} \mathrm{ZnO} / 70 \mathrm{~nm} \mathrm{Al}_{2} \mathrm{O}_{3}$ layer ( $\mathrm{ZnO}$ being first deposited).

it was observed when $\mathrm{ZnO} / \mathrm{Al}_{2} \mathrm{O}_{3}$ bilayers were $70 \mathrm{~nm} / 70 \mathrm{~nm}$ or $85 \mathrm{~nm} / 85 \mathrm{~nm}$ thick (the thickness values have an error bar around $\pm 5 \mathrm{~nm}$ ). Fig. $3 \mathrm{c}$ and $3 \mathrm{~d}$ represent the total transmittance in the range of $250-2500 \mathrm{~nm}$ for $70 \mathrm{~nm} \mathrm{ZnO/70} \mathrm{nm} \mathrm{Al}_{2} \mathrm{O}_{3}$ bilayer on Corning glass and on a AgNW network (previously deposited on Corning glass), respectively. In the visible wavelength range, from 380 to $700 \mathrm{~nm}$, the average value of total transmittance obtained for AgNW networks coated with $70 \mathrm{~nm}$ of $\mathrm{ZnO}$ was 64.9\%. Conversely, the total transmittance increased to $73.5 \%$ after an additional $70 \mathrm{~nm}$ thick layer of $\mathrm{Al}_{2} \mathrm{O}_{3}$ was deposited. Similarly, the transparency increased from $62.3 \%$ for networks coated with $85 \mathrm{~nm}$ of $\mathrm{ZnO}$ to $69.5 \%$ after an additional $85 \mathrm{~nm}$ thick layer of $\mathrm{Al}_{2} \mathrm{O}_{3}$ was deposited (results not shown).

After confirming the expected improvement in the optical transmittance of composites made with bilayer coatings of $\mathrm{ZnO} / \mathrm{Al}_{2} \mathrm{O}_{3}$, as compared to composites fabricated solely with $\mathrm{ZnO}$ coating, we evaluated the thermal stability of the former ones. Thus, the variations of the electrical resistance of $\mathrm{AgNW}$ networks coated with $\mathrm{ZnO}$ and $\mathrm{ZnO} / \mathrm{Al}_{2} \mathrm{O}_{3}$ were compared during thermal annealing up to $450{ }^{\circ} \mathrm{C}$ with a ramp of $2{ }^{\circ} \mathrm{C} \mathrm{min}$ -
1. In both cases, the initial electrical resistance was $30 \Omega$. Fig. $4 a$ shows the change in the electrical resistance of $\mathrm{ZnO}$-coated AgNWs after three consecutive thermal annealing ramps in air. During the first thermal annealing ramp, there is a decrease of the electrical resistance around $190{ }^{\circ} \mathrm{C}$ as a result of the sintering in the junctions between AgNWs. Increasing the temperature above $400{ }^{\circ} \mathrm{C}$ results in an irreversible change in the electrical resistance due to the diffusion of $\mathrm{Ag}$ atoms through the $\mathrm{ZnO}$ coating. This causes the resistance to reach $200 \Omega$ after three thermal cycles (up to $450{ }^{\circ} \mathrm{C}$ ). Fig. $4 \mathrm{~b}$ shows the change in electrical resistance of $\mathrm{ZnO} / \mathrm{Al}_{2} \mathrm{O}_{3}$-coated $\mathrm{AgNW}$ networks. As depicted here, the electrical resistance of the bilayer follows a linear relationship with the temperature, reaching $44.4 \Omega$ at $190{ }^{\circ} \mathrm{C}$. A further increase in temperature drives the optimization of the junctions between AgNWs, which causes a decrease of the electrical resistance to $14.5 \Omega$ at 320 ${ }^{\circ} \mathrm{C}$. The sintering process appears to stop at this temperature and a further increase of the temperature results in a linear increase of the electrical resistance. Upon cooling, a clear linear relationship between electrical resistance and temperature is 
a)

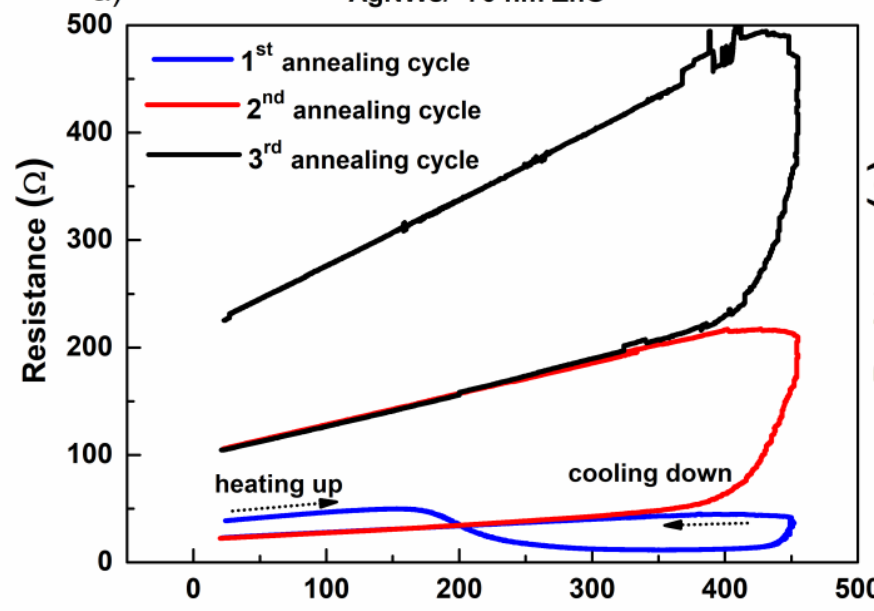

Temperature $\left({ }^{\circ} \mathrm{C}\right)$ b) $\mathrm{AgNWs} / 70 \mathrm{~nm} \mathrm{ZnO/} 70 \mathrm{~nm} \mathrm{Al} \mathrm{O}_{3}$

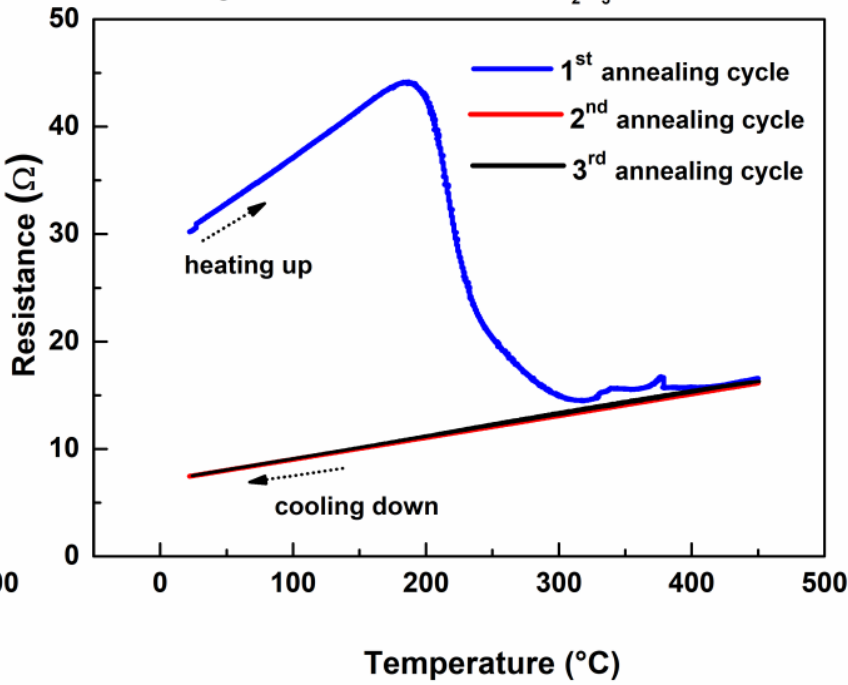

Figure 4. (a) In situ measured resistance of a $\mathrm{AgNW}$ network coated with $70 \mathrm{~nm}$ of $\mathrm{ZnO}$, during annealing in air from room temperature to $450{ }^{\circ} \mathrm{C}$ with a thermal ramp of $2^{\circ} \mathrm{C} \mathrm{min}^{-1}$. The first three cycles are shown. (b) In situ measured resistance of a $\mathrm{AgNW}$ network coated with $70 \mathrm{~nm} \mathrm{ZnO} / 70 \mathrm{~nm} \mathrm{Al}_{2} \mathrm{O}_{3}$ during annealing in air from room temperature to $450{ }^{\circ} \mathrm{C}$ with a thermal ramp of $2{ }^{\circ} \mathrm{C} \mathrm{min}-1$. The first three cycles are shown and a very good stability is observed.

again observed. After this initial cycle, the subsequent heatingcooling cycles merely showed the same linear dependency between resistance and temperature, with a temperature coefficient of resistivity of $2.7 \times 10^{-3} \mathrm{~K}^{-1}$ and without any irreversible change in the electrical resistance after each thermal cycle. It is also worth noticing the large difference of resistance ranges between Fig. $4 \mathrm{a}$ and Fig. $4 \mathrm{~b}$ while the thermal ramp conditions are identical: this illustrates as well the drastic effect of $\mathrm{ZnO} / \mathrm{Al}_{2} \mathrm{O}_{3}$ enhancement of stability of the coated $\mathrm{AgNW}$ networks. Further annealing cycles of $\mathrm{ZnO} / \mathrm{Al}_{2} \mathrm{O}_{3}$-coated network is reported in Fig. SI-5 in supplementary Information. During up to six cycles of annealing, the same linear dependency is observed. Therefore one can consider that a very good thermal stability has been reached at this stage.

It is worth noticing that $\mathrm{ZnO}$-coated AgNW networks exhibit enhanced stability after a long-duration storage under room conditions and away from direct sun light: after 770 days of storage the relative increase of electrical resistance was $37 \%$, $26 \%$ and $6 \%$, respectively, for bare AgNWs, $20 \mathrm{~nm}$ coated AgNWs and $40 \mathrm{~nm} \mathrm{ZnO} \mathrm{coated} \mathrm{AgNWs.} \mathrm{This} \mathrm{clearly} \mathrm{shows} \mathrm{the}$ stability enhancement when considering long term storage. A similar study for the $\mathrm{ZnO} / \mathrm{Al}_{2} \mathrm{O}_{3}$-coated networks is still missing and would clearly be of interest.

While the paper is mainly focused on fundamental research aspects, the potential integration of such transparent electrodes in different applications is also of crucial importance. The case of transparent heaters is rather obvious since the electrical insulating properties of $\mathrm{Al}_{2} \mathrm{O}_{3}$ can be used to insulate the conductive part (AgNW network) from the user. For LED and solar cells, where we deal respectively with injection and collection of charge carriers, the situation is less trivial. For these two applications, the integration can be discussed differently for bottom and top electrode. For the bottom electrode and for organic photovoltaic (OPV) devices, the bottom electrode is not supposed to have any anti-reflective coating therefore $\mathrm{ZnO}$ (or even better Al-doped $\mathrm{ZnO}$ ) could be used. Concerning the top electrode, one concern is the temperature of the SALD coating since the active layers of OPV devices and OLEDs cannot withstand high temperatures (typically $<120{ }^{\circ} \mathrm{C}$ ). As already discussed in the article the optimization of these nanocomposites concerns several aspects including also the SALD conditions (including coating temperature). Increasing the coating temperature leads generally to better metallic oxide layers (more crystallized and compact layer), ${ }^{47-49}$ however, for thermally sensitive substrates, plasma-enhanced SALD can be employed to significantly lower processing temperature $\left(<150{ }^{\circ} \mathrm{C}\right) .50,51$ Therefore SALD coating deposition at low temperature is possible, potentially associated with a slight drawback effect on certain physical properties of the coated layers. In parallel AgNW networks can be optimized without the need of thermal treatment, this depends on the AgNW synthesis conditions (the latter probably leading to different AgNW surface chemistry). Finally the positive effects of the $\mathrm{Al}_{2} \mathrm{O}_{3}$ coating demonstrated in this paper concern thermal and electrical stability as well antireflective coating, but $\mathrm{Al}_{2} \mathrm{O}_{3}$ layer could also be foreseen as a coating for the final device (i.e. over $\mathrm{AgNWs} / \mathrm{ZnO} /$ metallization) since $\mathrm{Al}_{2} \mathrm{O}_{3}$ coating is known to be an efficient gas and humidity barrier, ${ }^{52}$ ensuring also then a better lifetime and performances of devices.

\section{4 Mechanical flexibility of $\mathrm{AgNWs} / \mathrm{ZnO}$ and $\mathrm{AgNWs} / \mathrm{ZnO} / \mathrm{Al}_{2} \mathrm{O}_{3}$} composite electrodes

AgNW networks are well known for their very good mechanical stability under external bending or stretching tests, which makes them a perfect candidate to be integrated into flexible electronic devices. ${ }^{7}$ The applied external bending stress is distributed through the nanowire network, without strongly 
affecting each individual nanowire. Therefore the electrical resistance can remain constant even when a mechanical stress is applied. ${ }^{53-55} \mathrm{Here}$, the effect of $\mathrm{ZnO}$ and $\mathrm{ZnO} / \mathrm{Al}_{2} \mathrm{O}_{3}$ coatings on the mechanical flexibility of AgNW networks was examined to compare the mechanical behaviour of these composites to conventional ITO films. We used a commercial ITO-coated flexible polyethylene terephthalate (PET) substrate with ITO thickness of $300 \mathrm{~nm}$ and sheet resistance of $60 \Omega \mathrm{Sq}^{-1}$. In order to perform in situ measurements of mechanical flexibility, AgNW networks and metal oxide coatings were deposited on Neopulim substrates and the electrical resistance was measured during 10,000 cycles of mechanical bending with a bending radius of $5 \mathrm{~mm}$. As shown in Fig. $5 \mathrm{a}$, the bending test confirmed that similarly to bare networks, both $\mathrm{ZnO}$ and $\mathrm{ZnO} /$ $\mathrm{Al}_{2} \mathrm{O}_{3}$ encapsulated AgNWs exhibit mechanical stability much better compared to ITO (there is about 40 times less relative electrical resistance increase after 10,000 bending cycles for $\mathrm{ZnO} / \mathrm{Al}_{2} \mathrm{O}_{3}$ encapsulated AgNWs when compared to ITO). However, $\quad \mathrm{ZnO} / \mathrm{Al}_{2} \mathrm{O}_{3}$ encapsulated AgNWs based nanocomposites exhibit more degradation due the larger thickness of the oxide coating when compared to $\mathrm{ZnO}$ and bare AgNW networks. The resistance of the ITO electrode reached 2 $\mathrm{k} \Omega$ after only 100 cycles of bending, while the bare AgNW networks only showed $11.4 \%$ increase of electrical resistance after 10,000 cycles of bending. The increase in resistance for AgNW networks coated with $40 \mathrm{~nm}$ of $\mathrm{ZnO}$ was only a $4.7 \%$ after similar bending cycles. This improvement in the stability can be explained by superior adhesion of AgNWs to the substrate thanks to the ZnO coating, which prevents the separation of AgNWs from the substrate during the bending cycles.
Moreover, as shown in Fig. 5b, there was no trace of cracks in the $\mathrm{ZnO}$ coating after bending.

It has been already reported in literature that thin metal oxides films deposited on polymeric substrates, such as $\mathrm{ZnO}$ on polyethersulfone (PES) substrates, can endure rather high tensile and compressive strain before fracture. This has been demonstrated either on sputtered $\mathrm{Al}: \mathrm{ZnO},{ }^{56}$ sputtered ITO ${ }^{57}$ or ALD deposited $\mathrm{Al}_{2} \mathrm{O}_{3}{ }^{58}$ on polymeric substrates with a strong dependency of the critical tensile and compressive strain on oxide film thickness.

Thermal annealing of bare and $\mathrm{ZnO}$-coated AgNW network after bending cycles has been performed and the evolution of their electrical resistance is reported in Fig. SI-6 (see the supplementary information). While the resistance of bare AgNW network increased from $18 \Omega$ to $21 \Omega$, after annealing up to $285^{\circ} \mathrm{C}$ and cooling back to room temperature, $\mathrm{ZnO}$-coated AgNW network shows no change in electrical resistance (17.4 $\Omega$ before and after annealing). Superior thermal stability of $\mathrm{ZnO}$ coated AgNW network is another proof that thin $\mathrm{ZnO}$ coating remains an efficient coating even after 10,000 cycles of bending with bending radius of $5 \mathrm{~mm}$.

Finally, bending tests have been performed on bilayer coatings ( $60 \mathrm{~nm} \mathrm{ZnO} / 60 \mathrm{~nm} \mathrm{Al}_{2} \mathrm{O}_{3}$ ) on AgNWs and showed a rather high increase, $45 \%$, in the electrical resistance after 10,000 bending cycles. Major cracks in the direction perpendicular to the bending were observed by SEM images as shown in Fig. 5c. Therefore, bilayer coatings exhibit weaker mechanical flexibility as compared to the sole $\mathrm{ZnO}$ coating. One reason behind this behaviour is the overall higher thickness of bilayers as compared to $\mathrm{ZnO}$ coatings. As discussed above the thicker the a)

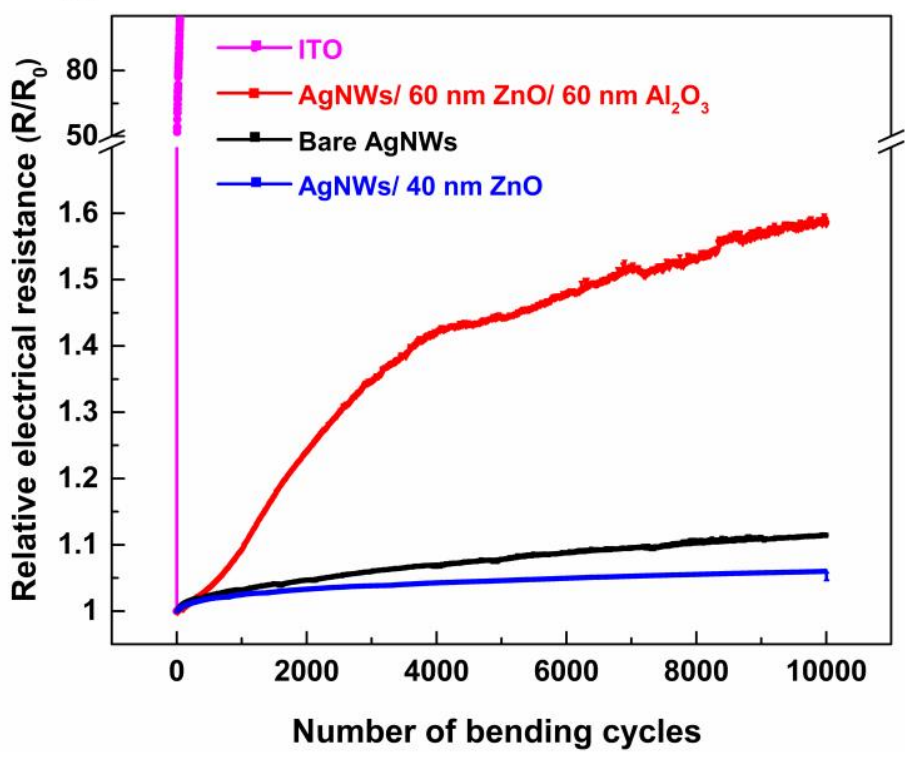

b)

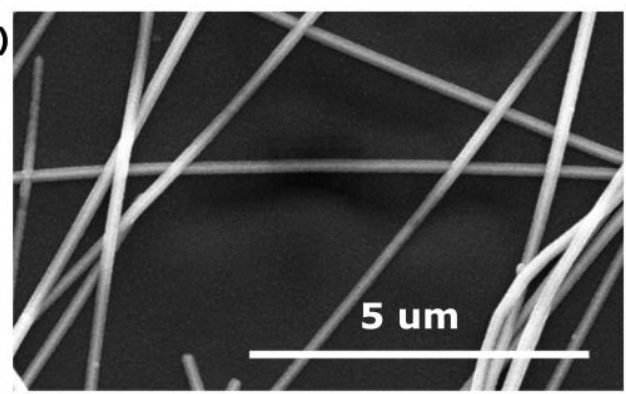

c)

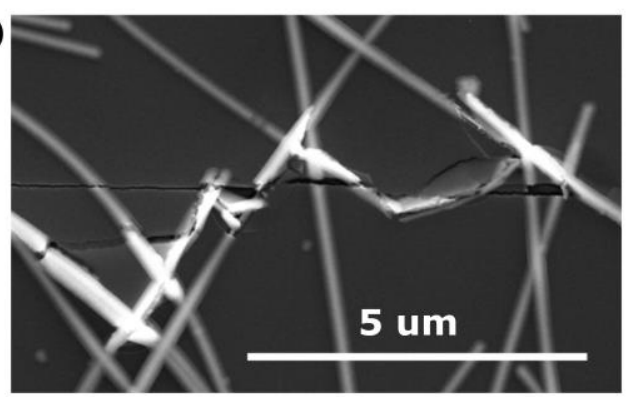

Figure 5. (a) Relative variation of electrical resistance of ITO on PEN, and bare, $40 \mathrm{~nm} \mathrm{ZnO}$ and $60 \mathrm{~nm} \mathrm{ZnO} / 60 \mathrm{~nm} \mathrm{Al} 2 \mathrm{O}_{3}-\mathrm{coated} \mathrm{AgNW}$ networks on Neopulim during 10,000 cycles of bending with bending radius of $5 \mathrm{~mm}$. (b) SEM observation reveals the absence of crack in the $40 \mathrm{~nm} \mathrm{ZnO}$ coated AgNW network after 10,000 cycles of bending. (c) SEM image of cracks observed in a $60 \mathrm{~nm} \mathrm{ZnO/60} \mathrm{nm} \mathrm{Al} \mathrm{O}_{3}$-coated AgNW network. after 10000 cycles of bending. 
films the lower the strain required to initiate the crack formation. Furthermore, there might be a difference in the critical strain of $\mathrm{Al}_{2} \mathrm{O}_{3}$ and $\mathrm{ZnO}$ coatings. Chawla et al. have studied the mechanical flexibility of ALD-coated $\mathrm{ZnO}, \mathrm{Al}_{2} \mathrm{O}_{3}$ and $\mathrm{ZnO} / \mathrm{Al}_{2} \mathrm{O}_{3}$ nanolaminates on PET substrates. ${ }^{59}$ They showed that $\mathrm{Al}_{2} \mathrm{O}_{3}$ and bilayer films have lower failure strains compared to $\mathrm{ZnO}$ films.

Depending on the targeted application, the thickness of each $\mathrm{ZnO}$ and $\mathrm{Al}_{2} \mathrm{O}_{3}$ layer has to be optimized since a trade-off has to be considered. Generally speaking, thicker metal oxide layers on AgNW networks lead to better thermal and electrical stability but also to lower optical transmittance and mechanical stability. A systemic research design could be used to optimize the main properties of the transparent electrodes based on such nanocomposites, knowing that such an optimization will be clearly application-dependent and can be also performed by adjusting the AgNW network density.

The present work can find applications in several domains. A direct connection can be linked with the work of Chen et al. who showed that $\mathrm{ZnO}$ coated AgNW networks embedded within the surface of a polyimide matrix can constitute an efficient flexible transparent electrode. ${ }^{60}$ The latter was shown to withstand thermal processing at $300^{\circ} \mathrm{C}$ for at least $6 \mathrm{~h}$ with little properties change. Such a freestanding electrode can for instance be used for the fabrication of a white polymer light emitting diode (PLED). ${ }^{60}$ Also while the present work focuses on coated AgNW networks it could also be useful for other nanostructures, such as Ag nanoparticle networks, especially when used in devices that should withstand relatively high temperatures. An interesting example is reported in the work of Joh et al. who fabricated multifunctional temperature-strain sensors that are capable of detecting simultaneously temperature and strain up to a temperature of $400{ }^{\circ} \mathrm{C},{ }^{61}$ with potential applications in bioelectronics and robotics.

\section{Conclusion}

A bilayer coating of $\mathrm{ZnO} / \mathrm{Al}_{2} \mathrm{O}_{3}$ over $\mathrm{AgNW}$ s has been proposed and tested as an alternative to $\mathrm{AgNW}$ networks with single coating by $\mathrm{ZnO}$ or $\mathrm{Al}_{2} \mathrm{O}_{3}$. The additional $\mathrm{Al}_{2} \mathrm{O}_{3}$ coating on top of the initial $\mathrm{ZnO}$ layer allows to obtain a resulting material which acts as an efficient antireflective coating: while a $70 \mathrm{~nm}$ thick ZnO coating on AgNW networks shows an average transmittance in the visible range - from 380 to $700 \mathrm{~nm}$ - of $64.9 \%$, bilayer coatings consisting of $70 \mathrm{~nm} \mathrm{ZnO} / 70 \mathrm{~nm} \mathrm{Al}_{2} \mathrm{O}_{3}$ on AgNWs show an average transmittance of $73.5 \%$. This improvement in the total transmittance is also associated with a superior thermal stability of bilayer coatings compared to that of $\mathrm{ZnO}$ single layer coating. Mechanical bending tests showed that composite electrodes of $\mathrm{ZnO}, \mathrm{Al}_{2} \mathrm{O}_{3}$ and $\mathrm{AgNWs}$ are still much more stable when compared to ITO-based electrodes. The best flexibility results were obtained for $\mathrm{ZnO}$-coated $\mathrm{AgNW}$ networks while the addition of the $\mathrm{Al}_{2} \mathrm{O}_{3}$ coating increases the total oxide thickness and partly limits the bending stability of bilayer composites. But still, the $\mathrm{ZnO} / \mathrm{Al}_{2} \mathrm{O}_{3}$ coated $\mathrm{AgNW}$ based transparent electrodes remain flexible. For instance, $\mathrm{ZnO} / \mathrm{Al}_{2} \mathrm{O}_{3}$ encapsulated AgNWs exhibit about 40 times less relative electrical resistance increase after 10,000 bending cycles compared to ITO. Therefore a compromise in terms of $\mathrm{ZnO}$ and $\mathrm{Al}_{2} \mathrm{O}_{3}$ thicknesses between enhanced stability and flexibility, as well as optical and electrical properties, has to be considered; such a compromise depends drastically on the targeted application. The results presented in this work indicate a path to low-cost, highly stable and transparent composite electrodes based on AgNWs and metal oxide coatings.

\section{Acknowledgments}

This work was supported by the European Joint Doctorate FunMAT program (H2020-MSCA-ITN-2014, Project ID 641640). This project was also partially supported by the French National Research Agency in the framework of the "Investissements d'avenir" program (ANR-15-IDEX-02) through the project EcoSESA and by the Belgian F.R.S.-FNRS project J.0124.19. This work was also performed within the framework of the Centre of Excellence of Multifunctional Architectured Materials "CEMAM" $n^{\circ}$ ANR-10-LABEX-44-01 through the project Earth. This work was funded by the Agence Nationale de Recherche (ANR, France) via the program ANR-16-CE05-0021 (DESPATCH), ANR-18-CE09-0041 (Meaning), ANR-18-CE09-0036 (Panassé) and ANR-15-CE05-0019 (Indeed). This work was as well supported by Région Auvergne Rhône-Alpes through the project Pack Ambition Recherche 2018 Eternité. The Carnot Energies du Futur is acknowledged through the project FREE. The authors would like to warmly thank Y. Bréchet, C. Celle, C. Arturo Masse De La Huerta, C. Mayousse, J. Resende, D. Papanastasiou, R. Rodriguez Lamas and J.P. Simonato for fruitful discussions.

\section{References}

1 D. Ginley, H. Hosono and D. C. Paine, Handbook of Transparent Conductors, Springer Science \& Business Media, 2010.

2 K. Ellmer, Nat. Photonics, 2012, 6, 809-817.

3 D. S. Hecht, L. Hu and G. Irvin, Adv. Mater., 2011, 23, 1482-1513.

4 A. Kumar and C. Zhou, ACS Nano, 2010, 4, 11-14.

5 T. M. Barnes, M. O. Reese, J. D. Bergeson, B. A. Larsen, J. L. Blackburn, M. C. Beard, J. Bult and J. van de Lagemaat, Adv. Energy Mater., 2012, 2, 353-360.

6 S. Ye, A. R. Rathmell, Z. Chen, I. E. Stewart and B. J. Wiley, Adv. Mater., 2014, 26, 6670-6687.

7 T. Sannicolo, M. Lagrange, A. Cabos, C. Celle, J.-P. Simonato and D. Bellet, Small, 2016, 12, 6052-6075.

8 D. Bellet, M. Lagrange, T. Sannicolo, S. Aghazadehchors, V. H. Nguyen, D. P. Langley, D. Muñoz-Rojas, C. Jiménez, Y. Bréchet and N. D. Nguyen, Materials, 2017, 10, 570.

9 M. Lagrange, D. P. Langley, G. Giusti, C. Jiménez, Y. Bréchet and D. Bellet, Nanoscale, 2015, 7, 17410-17423.

10 S. K. Choi and J. I. Lee, J. Vac. Sci. Technol. Vac. Surf. Films, 2001, 19, 2043-2047.

11 L. Hu, H. S. Kim, J.-Y. Lee, P. Peumans and Y. Cui, ACS Nano, 2010, 4, 2955-2963.

12 V. Scardaci, R. Coull, P. E. Lyons, D. Rickard and J. N. Coleman, Small, 2011, 7, 2621-2628

13 S. De, T. M. Higgins, P. E. Lyons, E. M. Doherty, P. N. Nirmalraj, W. J. Blau, J. J. Boland and J. N. Coleman, ACS Nano, 2009, 3, 1767-1774.

14 D. P. Langley, M. Lagrange, G. Giusti, C. Jiménez, Y. Bréchet, N. D. Nguyen and D. Bellet, Nanoscale, 2014, 6, 13535-13543. 
15 J. L. Zeng, Z. Cao, D. W. Yang, L. X. Sun and L. Zhang, J. Therm. Anal. Calorim., 2009, 101, 385-389.

16 H. Li, J. M. Biser, J. T. Perkins, S. Dutta, R. P. Vinci and H. M. Chan, J. Appl. Phys., 2008, 103, 024315.

17 T.-B. Song, Y. Chen, C.-H. Chung, Y. (Michael) Yang, B. Bob, H.-S. Duan, G. Li, K.-N. Tu, Y. Huang and Y. Yang, ACS Nano, 2014, 8, 2804-2811.

18 H. Tohmyoh and S. Fukui, J. Nanoparticle Res., , DOI:10.1007/s11051012-1116-x.

19 C. Mayousse, C. Celle, A. Fraczkiewicz and J.-P. Simonato, Nanoscale, 2015, 7, 2107-2115.

20 J. Jiu, J. Wang, T. Sugahara, S. Nagao, M. Nogi, H. Koga, K. Suganuma, M. Hara, E. Nakazawa and H. Uchida, RSC Adv., 2015, 5, 27657-27664.

21 C. Celle, A. Cabos, T. Fontecave, B. Laguitton, A. Benayad, L. Guettaz, N. Pélissier, V. H. Nguyen, D. Bellet, D. Muñoz-Rojas and J.-P. Simonato, Nanotechnology, 2018, 29, 085701.

22 A. Khan, V. H. Nguyen, D. Muñoz-Rojas, S. Aghazadehchors, C. Jiménez, N. D. Nguyen and D. Bellet, ACS Appl. Mater. Interfaces, 2018, 10, 19208-19217.

23 A. Kim, Y. Won, K. Woo, C.-H. Kim and J. Moon, ACS Nano, 2013, 7, 1081-1091.

24 A.-T. Pham, X.-Q. Nguyen, D.-H. Tran, V. Ngoc Phan, T.-T. Duong and D.C. Nguyen, Nanotechnology, 2016, 27, 335202.

25 X. Yan, J. Ma, H. Xu, C. Wang and Y. Liu, J. Phys. Appl. Phys., 2016, 49, 325103.

26 Q. Huang, W. Shen, X. Fang, G. Chen, Y. Yang, J. Huang, R. Tan and W. Song, ACS Appl. Mater. Interfaces, 2015, 7, 4299-4305.

27 T.-B. Song, Y. S. Rim, F. Liu, B. Bob, S. Ye, Y.-T. Hsieh and Y. Yang, ACS Appl. Mater. Interfaces, 2015, 7, 24601-24607.

28 B. Hwang, Y. An, H. Lee, E. Lee, S. Becker, Y.-H. Kim and H. Kim, Sci. Rep., 2017, 7, 41336 .

29 W. Shin, W. Cho and S. J. Baik, Mater. Res. Express, 2018, 5, 015050.

30 R. Liu, M. Tan, X. Zhang, L. Xu, J. Chen, Y. Chen, X. Tang and L. Wan, Sol. Energy Mater. Sol. Cells, 2018, 174, 584-592.

31 W. Lan, Z. Yang, Y. Zhang, Y. Wei, P. Wang, A. Abas, G. Tang, X. Zhang, J. Wang and E. Xie, Appl. Surf. Sci., 2018, 433, 821-828.

32 M. Göbelt, R. Keding, S. W. Schmitt, B. Hoffmann, S. Jäckle, M. Latzel, V. V. Radmilović, V. R. Radmilović, E. Spiecker and S. Christiansen, Nano Energy, 2015, 16, 196-206.

33 D. Muñoz-Rojas and J. MacManus-Driscoll, Mater. Horiz., 2014, 1, 314

34 V. H. Nguyen, J. Resende, D. T. Papanastasiou, N. Fontanals, C. Jiménez, D. Muñoz-Rojas and D. Bellet, Nanoscale, 2019, 11, 12097-12107.

35 T. Sannicolo, N. Charvin, L. Flandin, S. Kraus, D. T. Papanastasiou, C. Celle, J.-P. Simonato, D. Muñoz-Rojas, C. Jiménez and D. Bellet, ACS Nano, 2018, 12, 4648-4659.

36 D. P. Langley, M. Lagrange, N. D. Nguyen and D. Bellet, Nanoscale Horiz. 2018, 3, 545-550

37 D. Muñoz-Rojas, V. H. Nguyen, C. Masse de la Huerta, S. Aghazadehchors, C. Jiménez and D. Bellet, Comptes Rendus Phys., 2017 18, 391-400.

38 A. Bid, A. Bora and A. K. Raychaudhuri, Phys. Rev. B, , DOI:10.1103/PhysRevB.74.035426.

39 M. Lagrange, T. Sannicolo, D. Muñoz-Rojas, B. G. Lohan, A. Khan, M. Anikin, C. Jiménez, F. Bruckert, Y. Bréchet and D Bellet, Nanotechnology, 2017, 28, 055709 .

40 D.R. Lide, CRC Handbook of chemistry and physics 2004-2005: A ready reference book of chemical and physical data, CRC press, 2004.

41 N. V. Nguyen, O. A. Kirillov, W. Jiang, W. Wang, J. S. Suehle, P. D. Ye, Y. Xuan, N. Goel, K.-W. Choi, W. Tsai and S. Sayan, Appl. Phys. Lett., 2008, 93, 082105

42 E. O. Filatova and A. S. Konashuk, J. Phys. Chem. C, 2015, 119, 2075520761.

43 D. C. Miller, R. R. Foster, S.-H. Jen, J. A. Bertrand, S. J. Cunningham, A. S. Morris, Y.-C. Lee, S. M. George and M. L. Dunn, Sens. Actuators Phys., 2010, 164, 58-67.

44 M. Singh and M. Singh, Nanosci. Nanotechnol. Res., 2013, 1, 27-29.

$45 \mathrm{Ta} 2 \mathrm{O} 5 / \mathrm{Al} 2 \mathrm{O} 3 / \mathrm{SiO} 2$ - antireflective coating for non-planar optical surfaces by atomic layer deposition | (2017) | Pfeiffer | Publications | Spie, https://spie-org.gaelnomade1.grenet.fr/Publications/Proceedings/Paper/10.1117/12.2250272, (accessed September 20, 2018).
46 K. Marszałek, P. Winkowski and M. Marszałek, Mater. Sci.-Pol., 2015, 33, 6-10.

47 V. H. Nguyen et al., J. Renew. Sustain. Energy, 2017, 9, 021203.

48 A. Illiberi, F. Roozeboom and P. Poodt, ACS Appl. Mater. Interfaces, 2012, 4, 268-272.

49 A. Illiberi, R. Scherpenborg, Y. Wu, F. Roozeboom and P. Poodt, ACS Appl. Mater. Interfaces, 2013, 5, 13124-13128.

50 L. Hoffmann, D. Theirich, D. Schlamm, T. Hasselmann, S. Pack, K. O. Brinkmann, D. Rogalla, S. Peters, A. Räupke, H. Gargouri and T. Riedl, J. Vac. Sci. Technol. A, 2017, 36, 01A112.

51 F. J. van den Bruele, M. Smets, A. Illiberi, Y. Creyghton, P. Buskens, F. Roozeboom and P. Poodt, J. Vac. Sci. Technol. A, 2014, 33, $01 \mathrm{~A} 131$.

52 A. A. Dameron, S. D. Davidson, B. B. Burton, P. F. Carcia, R. S. McLean and S. M. George, J. Phys. Chem. C, 2008, 112, 4573-4580.

53 B. Hwang, H.-A.-S. Shin, T. Kim, Y.-C. Joo and S. M. Han, Small, 2014, n/a$n / a$.

54 P. Lee, J. Lee, H. Lee, J. Yeo, S. Hong, K. H. Nam, D. Lee, S. S. Lee and S. H. Ko, Adv. Mater., 2012, 24, 3326-3332.

55 M. S. Miller, J. C. O'Kane, A. Niec, R. S. Carmichael and T. B. Carmichael, ACS Appl. Mater. Interfaces, 2013, 5, 10165-10172.

56 B. C. Mohanty, H. R. Choi, Y. M. Choi and Y. S. Cho, J. Phys. Appl. Phys. 2011, 44, 025401

57 Y. Leterrier, L. Médico, F. Demarco, J.-A. E. Månson, U. Betz, M. F. Escolà, M. Kharrazi Olsson and F. Atamny, Thin Solid Films, 2004, 460, 156-166.

58 A. Bulusu, H. Behm, F. Sadeghi-Tohidi, H. Bahre, E. Baumert, D. Samet, C. Hopmann, J. Winter, O. Pierron and S. Graham, SID Symp. Dig. Tech. Pap., 2013, 44, 361-364.

59 V. Chawla, M. Ruoho, M. Weber, A. A. Chaaya, A. A. Taylor, C. Charmette, P. Miele, M. Bechelany, J. Michler and I. Utke, Nanomaterials, DOI:10.3390/nano9010088.

60 D. Chen, J. Liang, C. Liu, G. Saldanha, F. Zhao, K. Tong, J. Liu and Q. Pei, Adv. Funct. Mater., 2015, 25, 7512-7520.

61 H. Joh, W. S. Lee, M. S. Kang, M. Seong, H. Kim, J. Bang, S.-W. Lee, M. A Hossain and S. J. Oh, Chem. Mater., 2019, 31, 436-444. 